\title{
Current lifestyle of young adults treated for cancer in childhood
}

\author{
Sioned E Evans, Martin Radford
}

\begin{abstract}
The aim of this study was to look at the current lifestyle of young adult survivors of childhood cancer between the ages of 16 and 30 years to document their achievements and expose any psychosocial problems. Sixty six young adult survivors were contacted and asked if they and their siblings (16-30 years) would take part in a lifestyle study; 48 patients and 38 sibling controls were interviewed. This took the form of a structured lifestyle questionnaire, a self esteem questionnaire (Oxford Psychologists Press), and an unstructured interview.
\end{abstract}

Fifty five per cent of patients achieved five or more $A-C$ grades at ' $O$ ' level/GCSE compared with $62 \%$ of siblings and a national average of $30 \%$. Despite that these patients were significantly less likely to go on to higher education than their siblings. The two groups were equally employable and earning similar salaries. There were three cases of known employer prejudice. A slightly higher percentage of patients than siblings had their driving licence.

Seventeen patients felt their appearance had changed and eight felt that they had a residual physical mobility problem. Both groups were socially active and equally likely to partake in competitive sports. There was no overall difference in the self esteem of the two groups. In general the survivors of childhood cancer were coping well in their young adult life and achieving the same lifestyle goals as their siblings. However, significant problems have been identified.

(Arch Dis Child 1995; 72: 423-426)

Keywords: lifestyle, cancer.

Current figures show that one in every 600 children in the UK will develop cancer between birth and 16 years. Well over $50 \%$ of these children can now be expected to be cured. ${ }^{1}$ This recent improvement in prognosis has been due to advances in surgery, radiotherapy, and chemotherapy.

The medical problems encountered by survivors of childhood cancer are well documented. However, less work had been carried out on the psychosocial impact of surviving the illness. Previous studies into this area have varied in their conclusions. In 1975 Holmes and Holmes looked at survivors 10 years on and concluded that they had matured to live essentially normal lives. ${ }^{2}$ A Helsinki study in 1989 discovered that some subjects were at risk of developing emotional and social problems. ${ }^{3}$ Meadows et al concluded in their 1989 study that in general patients were functioning normally compared with their sibling controls but admitted that there were unexplored areas. $^{4}$

Potential psychosocial problems for these long term survivors of childhood cancer include difficulties in returning to school and forming relationships, poor educational achievements due to lengthy absenteeism, employer prejudice, insurance denial and adverse changes in cosmetic appearance, all resulting in a possible lack of self esteem. Current reports differ as to whether diagnosis at an older age increases the likelihood of encountering these problems. ${ }^{5}$

This present study concerns the lifestyle of a group of young adult survivors of childhood cancer with the aim of highlighting any psychosocial problems and documenting their achievements.

\section{Patients and methods}

PATIENTS

Patients eligible for this study were long term survivors of childhood cancer who were between the ages of 16 and 30 at the time of the study. Seventy five patients were identified from oncology registers at the department of child health, Southampton General Hospital and the adult oncology and radiotherapy departments at the Royal South Hampshire Hospital in Southampton.

Sixty six patients were finally contacted. Of the remaining nine eligible patients who were not contacted six were of unknown address and there were three patients who were not contacted as the clinicians dealing with their follow up care advised against them taking part in the study. One of these patients was schizophrenic and the other two were wheelchair bound.

\section{CONTROL GROUP}

The control group for this study was made up of siblings of survivors of childhood cancer also between the ages of 16 and 30 . However, there were only 33 eligible siblings within this group and so a further five eligible siblings were identified from a group of children currently on treatment for childhood cancer.

\section{METHOD}

A letter was sent to all eligible patients explaining the nature of the study and asking if they would like to take part. The letter also asked if 
they had any siblings aged between 16 and 30 who would be willing to participate. Each letter was signed by the relevant clinician dealing with the patient's follow up. The letter was sent out together with a return slip and a stamped, addressed envelope for prompt reply.

The 50 patients who agreed to take part were contacted by telephone. A suitable time was then arranged for the interview to take place. Thirty eight patients were interviewed in the department of child health at Southampton General Hospital, four patients were interviewed at home, and eight patients who were unable to attend for interview were sent their questionnaires together with instructions to complete by themselves. Siblings and patients were encouraged to come along together.

The interview took the form of two questionnaires and an unstructured interview. The first was a structured questionnaire that consisted of questions about their illness and their current lifestyle. The second was a standard adult self esteem questionnaire from the Oxford Psychologists Press that consisted of 25 statements beside which were true and false boxes. Both questionnaires were answered by patients and siblings but irrelevant questions were omitted for siblings. The unstructured interview gave both patients and siblings an opportunity to talk about their own experiences of childhood cancer.

Data obtained from the questionnaire was analysed using SPSS statistic programme.

\section{Results}

Of the 50 patients who agreed to participate 48 were finally interviewed. Their original diagnoses included central nervous system tumours (8), acute lymphoblastic leukaemia (7), acute myeloblastic leukaemia (1), and various solid tumours (32). Twenty six patients were male and 22 female. The interval between completion of treatment and interview was $>5$ years in 32 patients and $<5$ years in 16. All patients with central nervous system tumours and all patients with acute lymphoblastic leukaemia had received cranial irradiation.

Thirty three siblings of patients who had completed treatment were interviewed. Five siblings of patients currently receiving treatment were also interviewed. The mean age of patients and siblings in this study was 20 and 21 years respectively.

\section{EDUCATION}

There was no significant difference between patients and siblings in achieving qualifications at 16 years; 26 patients $(55 \%)$ and 23 siblings $(62 \%)$ achieved five or more $\mathrm{A}-\mathrm{C}$ grades at ' $\mathrm{O}$ ' level or GCSE. These compare favourably with the national average of $30 \%$ quoted from the 1991 National Consortium for Examination Results. ${ }^{6}$ Four patients and one sibling had no qualifications at school leaving age. However, in spite of the promising results, patients were significantly less likely to go on to higher education ( 16 years onwards) than their siblings. Twelve (25\%) patients and 18 siblings $(48 \%)$ continued on to higher education $(\mathrm{p}<0.05$ Mantel-Haenszel test). The national average figure quoted for this result is $17 \cdot 3 \%$.

Thirty two patients (67\%) and four siblings $(10 \%)$ felt that their education had suffered as a result of their or their sibling's illness. The majority of patients felt that their re-entry into school had not been a problem but lack of communication and liaison between teachers, parents, and medical staff appeared to be the main cause of any problems that did arise.

\section{EMPLOYMENT}

Of the 48 patients 14 were still in education, 27 were in paid employment, two were housewives, one was travelling, and four were unemployed. There was no significant difference between the annual salaries of patients and siblings. Three patients said that they had been turned down from job applications because they stated that they had been treated for childhood cancer.

\section{DRIVING TEST}

Thirty six patients $(75 \%)$ and 22 siblings $(58 \%)$ had their driving licence. The national average quoted by the Department of Transport for 17-30 year olds currently holding a UK driving licence was $55 \cdot 4 \%$. However, there was no significant difference in the number of patients and siblings who passed their test at first attempt. Twenty five patients $(52 \%)$ and 20 siblings (53\%) passed first time. The national average quoted for this figure is $45 \%$.

\section{MARITAL STATUS AND FERTILITY}

Thirteen patients $(27 \%)$ and seven siblings $(19 \%)$ were in long term stable relationships. This was defined as those who were married, engaged, or cohabiting. The number of offspring in both the patient and sibling group was low. Two patients had one child each. No other patients had any children. In the control group, two siblings had two and three children respectively.

\section{MORTGAGE, CREDIT, AND INSURANCE}

Nine patients $(19 \%)$ and six siblings (16\%) owned their own accommodation. All had been successful in their mortgage application. No long term survivors had been denied credit. Eight patients $(17 \%)$ reported being denied life or health insurance or having to pay higher premiums because of their history of childhood cancer.

\section{SOCIAL ACTIVITY}

Twenty four patients $(51 \%)$ and 15 siblings $(39 \%)$ were members of a group or team. An almost equal number of patients $(51 \%)$ and siblings $(55 \%)$ took part in competitive sports. This result is in spite of those survivors of childhood cancer of the central nervous system 
who were advised against playing contact sports.

Seventeen patients $(36 \%)$ felt that their appearance had changed as a result of their illness or its treatment. Subjective cosmetic complaints included uneven hair growth, embarrassing scars, and thinning of the neck after radiotherapy to the neck. Eight patients felt that they had a residual mobility problem.

\section{SELF ESTEEM}

There was no significant difference in overall self esteem of patients and siblings as measured by the Oxford Psychologists Press adult self esteem questionnaire. Thirty patients $(63 \%)$ and 23 siblings $(61 \%)$ had high self esteem as measured by this technique.

\section{UNSTRUCTURED INTERVIEW}

Some patients, especially those diagnosed at a very early age, did not feel as though the experience had changed them in any way. About half the patients felt that in their opinion they had 'changed for the better'. Some felt they had become more appreciative of life having been given a second chance to live while a number felt they had 'grown up' much earlier than their contemporaries. However, five patients admitted that the illness had affected them adversely, making them more cynical, less confident, and more introverted. Interestingly, five long term survivors had decided to enter medical professions as a direct result of their experiences.

\section{Discussion}

It can be seen from this study that in general the long term survivors are coping well with young adult life and achieving the same lifestyle goals as their siblings and the nation as a whole.

The use of siblings as a control group was not an ideal choice as they may also encounter stresses related to their brother/sister's illness. However, it is difficult to find an equivalent group who would control as well for environmental and socioeconomic factors. The additional comparison with a national average also had its limitations; even though the age range for the national average figures and the study were the same, the age distribution was different. The reason for the younger bias of patients is presumably that there have been more survivors of childhood cancer in recent years. A study using an older population would be of more use when looking at certain aspects of lifestyle such as fertility, employment status, and long term relationships.

The number of survivors with central nervous system tumours in this study was possibly too small to make firm conclusions about their lifestyle. More research looking at survivors of central nervous system tumours alone would be beneficial. Furthermore, the two wheelchair bound patients who were not contacted may have provided useful information about their experiences. More detailed information was obtained for this study when both patients and siblings were interviewed together. It was, therefore, disappointing that only one third of siblings came along for interview and that $12 \%$ of patients were sent their questionnaires to complete alone.

In spite of two thirds of the patients stating that their education had suffered as a result of their illness, their ' $O$ ' level/GCSE qualifications compared well with their siblings. This could be a reflection of their determination to succeed in life. However, a discrepancy occurs because even though they are achieving the necessary academic qualifications to go on to higher education, significantly fewer patients than siblings actually do. This is difficult to explain but may be associated with a lack of independence in some or that they find more security in finding a job. Alternatively, some parents may still be very overprotective of their children and encourage them to find a job rather than move away from home to pursue a university or polytechnic course.

Some patients reported having problems returning to school. For the majority, these turned out to be temporary ones. In fact, improvements have been carried out recently to facilitate the child's return to school. Information booklets such as Welcome Back! by Isobel Larcombe are now available to teachers. ${ }^{7}$ One-to-one interviews between medical staff and teachers have been shown to be extremely beneficial, ${ }^{8}$ while continuous links between the child and school throughout treatment appeared to ease the return to school. Some of the long term survivors remembered that having returned to school, they seemed to miss the same subject each week because of their continuing outpatient treatment/follow up. An ideal situation would be to have the outpatient appointment on a different day each time but this would obviously cause difficulties in administration and treatment regimens.

In general, the patients in the study did not find home tutors useful as they remember either feeling too ill to concentrate or the work being of the wrong standard. Unemployment in this study was defined as those young adults between the ages of 16 and 30 who had completed their full time education and were currently seeking employment. Patients and siblings were found to be equally employable and earning similar salaries. Three patients felt that they had experienced employer prejudice. Possibly an information booklet could be designed to be given to companies who are known to discriminate against survivors of childhood cancer. Many survivors felt that teachers, parents, and doctors should encourage patients to pursue the career they wish. The driving test, which is a social indicator of skill, self confidence and ability to learn a new task, encouragingly showed that patients are as likely as their siblings to have their driving licence and to pass it at first attempt.

There appeared to be no problems for patients securing a mortgage or in credit applications. However, some patients 
expressed difficulty in obtaining insurances. It is understandable that insurance companies see childhood cancer survivors as a 'risk' category. However, the companies that do not even consider applications should have clarification and reinforcement from a doctor that the applicant is fully cured of their childhood cancer.

It is encouraging that in this study, patients and siblings are equally likely to be in a stable relationship and have children. Advice and counselling should be available, however, for those couples where infertility is a potential problem.

Problems with physical mobility were reported by $8 \%$ of the long term survivors. This was a disappointment for the majority who could no longer participate in team sports. Therefore, they should be encouraged to take up a sport they are able to do and enjoy. Activity holidays for children currently on treatment and long term survivors are organised by many paediatric oncology centres around the country. These were not only found to be great fun but gave them the knowledge that they could be as active as their peers.

Generally the survivors in this study had a determination to lead a full active life. However, a few patients cited their illness as a reason for lacking self confidence socially. They felt that isolation from friends and their subsequent lack of understanding contributed to this. This situation is avoidable for most patients and highlights the continuing need for interprofessional liaison.

During the unstructured interviews, a number of patients said that they wished they had remained in contact with other childhood cancer patients they had met on the wards. The formation of a 'social network' for long term survivors would be an idea with the group meeting up occasionally and this may also help them to readjust to 'normal' life.

A final point of interest that emerged from the study was that quite a number of adult survivors volunteered their services to help children currently on treatment. This should be encouraged as logically it would be of great help to both childhood cancer patients and their parents if they could see a group of young adult survivors living active lives.

\section{Conclusion}

In this study of young adult survivors of childhood cancer, it was demonstrated that there was no significant difference between patients and siblings in their educational achievements at ' $O$ ' level/GCSE, employment status and salary earned, driving test achievements, establishing relationships, and partaking in societies and competitive sports. Their overall self esteem was as high as their siblings. However, significant problems were exposed. Sixty seven per cent of patients felt their education had suffered and they were significantly less likely to pursue their education. Twenty two per cent of patients had residual physical mobility problems while $36 \%$ of patients felt their appearance had changed. Some were still experiencing employer prejudice and discrimination from insurance policies. On an individual level, patients lacked self confidence and had become more cynical and resentful, blaming this upon their experiences of childhood cancer.

Changing prognoses bring changing needs and even though patients in general appear to be coping well with young adult life, there are still areas where improvements can be made to ensure a good quality of life for survivors of childhood cancer.

1 Kohler JA. Recent advances in management of paediatric cancer. Postgraduate Update May 1991: 950-60.

2 Holmes HA, Holmes FF. After ten years, what are the handicaps and lifestyles of children treated for cancer? Clin Pediatr (Phila) 1975; 14: 819-23.

3 Makipernace A. Long term quality of life and psycho-social coping after treatment of solid tumours in childhood. Acta Paediatr Scand 1989; 78: 728-35.

4 Meadows AT, McKee L, Kazak AE. Psycho-social status of young adult survivors - a survey. Med Pediatr Oncol 1989; 17: 466-70.

5 Eiser C. Chronic childhood disease. An introduction to psychological theory and research. Cambridge: Cambridge University Press, 1990.

6 National Consortium for Examination Results. Examination results: GCSE results, year 11. 1991. Available from: Peter Richmond, NCER Secretary, NCER, Education Services Group, County Hall, Chester CH1 1SQ.

7 Larcombe I. Welcome back! How teachers can help children returning to school after treatment for cancer. London: Cancer Research Campaign, 1991.

8 Stevens MCG, Kaye JI, Kenwood CF, Mann JR. Facts for teachers of children with cancer. Arch Dis Child 1988; 63: 456-8. 